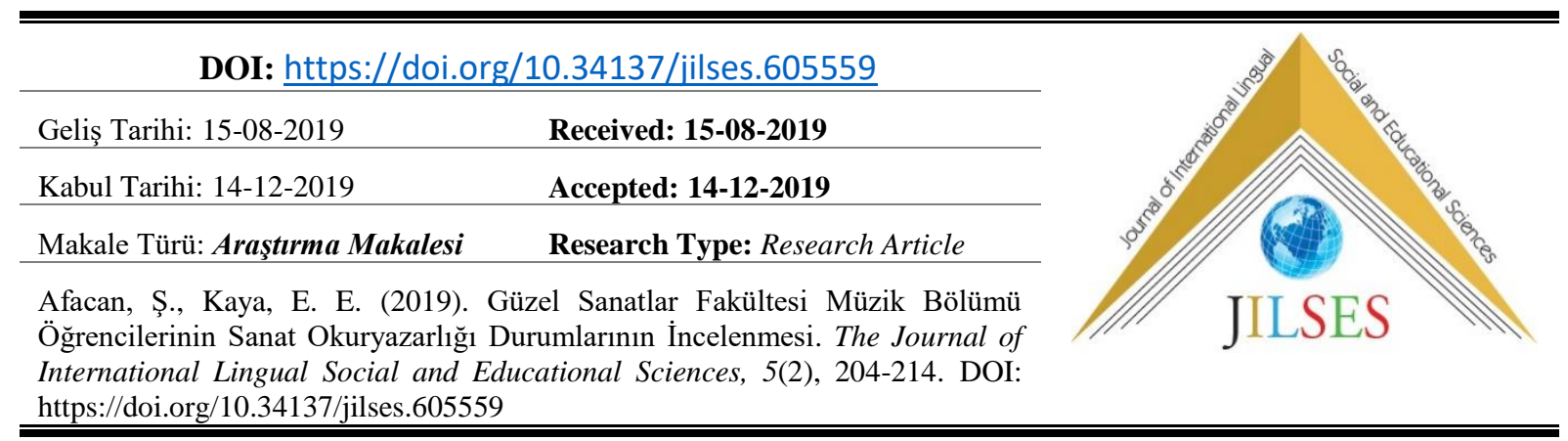

\title{
Güzel Sanatlar Fakültesi Müzik Bölümü Öğrencilerinin Sanat Okuryazarlığı Durumlarının İncelenmesi *
}

\section{Şenol AFACAN ${ }^{1}$ Emin Erdem KAYA ${ }^{2}$}

$\ddot{\mathbf{O z}}$

Sanat okuryazarlı̆̆ının diğer okuryazarlık kavramları arasında güzel sanatlar eğitimi alan öğrenciler için farklı bir önem taşıdı ̆̆ söylenebilir. Güzel sanatlar fakültelerinde öğrenim gören ögrrencilerin alana özgü sanat okuryazarlığı kazanmış olmaları aynı zamanda bireysel donanımları açısından istenilen özelliklerdendir. Güzel sanatlar fakülteleri müzik bölümü öğrencilerinin sanat okuryazarlık durumlarını belirlemek amacıyla yapılan bu çalışmanın örneklemini 2018-2019 eğitim öğretim yılında Kırşehir Ahi Evran Üniversitesi Neşet Ertaş Güzel Sanatlar Fakültesi Müzik Bölümü 1 ve 2. sinıflarında öğrenim gören 45, Nevşehir Hacı Bektaş Veli Üniversitesi Güzel Sanatlar Fakültesi Müzik Bölümü 1 ve 2.sinıflarında öğrenim gören 57 olmak üzere toplam 102 öğrenci oluşturmaktadır. Araştırmanın modeli nicel araştırmalar içinde yer alan tarama modelidir. Çalışmada veri toplama aracı olarak Yücetoker (2014) tarafindan geliştirilen ve dört faktörden oluşan "Sanat okuryazarlı̆̆ ölçeği”" kullanılmıştır. Ölçeğin güvenirlik katsayısı (Cronbach Alpha).912'dir. Veriler analizinde SPSS programı kullanılmıştır. Yapılan çalışma sonucunda araştırma grubundaki öğrencilerin sanat okuryazarlı̆̆ durumlarının cinsiyet, ögrenim gördükleri üniversite, sanat kitaplarl okumaktan hoşlanma ve kütüphanede araştırma yapmayı sevme değişkenleri açısından anlamlı farklılık gösterdiği belirlenmişstir. Sanat okuryazarlığ durumunun sınıf seviyesine göre değişmediği ortaya çımııstır.

Anahtar Kelimeler: Güzel Sanatlar Fakültesi, Müzik Bölümü, Sanat Okuryazarlı̆̆

\section{Examination of Art Literacy Situations of Students of Fine Arts Faculty Music Department}

\begin{abstract}
Among the other literacy concepts of art literacy, it can be said that it has a different importance for the students who receive fine arts education. The fact that students studying in the faculties of fine arts have acquired art literacy specific to the area is also a desired feature in terms of individual equipment. This study was carried out to determine the art literacy status of the music faculty students of Fine Arts Faculties. In 20182019 academic year, Kırșehir Ahi Evran University Neșet Ertaş Fine Arts Faculty Music Department 1 and 2 classes. A total of 102 students, 57 of whom are in the 1st and 2nd grades of the department. The model of the study is the screening model included in quantitative research. As the data collection to "Art literacy scale"developed by Yücetoker (2014) was used in the study. The cronbach alpha reliability of the scale was calculated to be .912. In the statistical analysis of the data, SPSS was used. As a result of the study, it was determined that the art literacy status of the students in the research group showed a significant difference in terms of gender, liking reading university, art books and liking to do research in the library. It was found that the status of art literacy did not change according to class level.
\end{abstract}

Key words: Fine Arts Faculty, Music Department, Art Literacy

\footnotetext{
* Bu çalışma VI. Uluslararası Güzel Sanatlar Sempozyumu'nda (Asos Congress, 2019) sunulan sözlü bildirinin genişletilmiş versiyonudur.

${ }^{1}$ Dr. Öğr. Üyesi, Kırşehir Ahi Evran Üniversitesi, senolafacan@gmail.com, http://orcid.org/0000-0001-7564-1695

2 Doç. Dr. Nevşehir Hacı Bektaş Veli Üniversitesi, erdemky@gmail.com, http://orcid.org/0000-0003-0548-9864
} 


\section{Giriş}

Sanat insan yaşamının her döneminde yer alan bir olgudur. Yalın bir ifadeyle sanat duygu, düşünce ve izlenimleri, belli durum olgu ve olayları, belirli bir amaç ve yöntemle belirli bir güzellik anlayışına göre işlenerek birleştirilmiş özgün estetik bir bütündür (Uçan, 1996).

Sanat çok yönlü ve boyutlu olguyu türlü biçimleriyle yaşayarak eğitilen ve yetişen çocuk ve gencin, olay ve olguları yorumlayabilen, kavrayabilen, yeniliklere, çağdaş her türlü gelişmeye açık, bilim, teknoloji ve toplumsal değişme süreçlerindeki yeni gelişmeleri anlamaya yatkın, hoşgörülü aynı zamanda dinamik bir kişilik geliştireceği kesindir (San, 1982). Sanat eğitimi çağdaş eğitimin ayrılmaz bir parçasıdır. Sanat eğitimi bireye kendi yaşantısı yoluyla önceden belirlenmiş sanatsal davranışlar kazandırma ve geliştirme sürecidir. Sanat eğitimi bireysel, eğitimsel, toplumsal, ekonomik ve kültürel işlevleri ile bireyi ve toplumları yönlendiren geliştiren bir yapıya sahiptir.

Sanat eğitiminin en önemli boyutlarından biri olan müzik eğitimi günümüzde alana özgü teknik bilgi ve beceri kazandırmanın yanında sanatsal bir bakış açısına sahip olmayı, sanatsal bilgilere ulaşmayı, analiz ve sentez yaparak çok boyutlu düşünmeyi gerekli kılmaktadır. Bu anlamda sanat okuryazarlığı ön plana çıkmaktadır. Günümüzde pek çok alana özgü okuryazarlık kavramları kullanılmaktadır. Müzik okuryazarlığı, medya okuryazarlı̆̆ yazarlığı ve görsel okuryazarlık bunlara örnek verilebilir. Aynı zamanda bu okuryazarlık türlerinin incelendiği araştırmalar da mevcuttur (Afacan ve Şentürk, 2016; Aslan ve Deniz, 2011; Aydın ve Silik, 2018; Çakmak, 2019; Kaya ve Bacanak, 2013; Kolburan Geçer ve Dağ, 2010; Örs ve Baş, 2018; Uyar ve Temiz, 2019; Yenice, Yavaşoğlu, Alpak Tunç ve Candarlı Arıkoz, 2019).

Okuryazarlık, bir bireyin günlük yaşamdaki kısa, basit ifadeleri anlayarak okuma ve yazma yeteneğini ifade eder (Keefe ve Copeland, 2011). Okuryazarlık, yazılı veya görsel semboller kullanarak bireyler arasındaki iletişimi sağlayacak düzeyde okuma ve yazma yeteneğidir. Günümüzde okuryazarlık, belli bir alanda geniş bir bilgiye sahip, iyi eğitimli bir kişiye atıfta bulunmak için de kullanılmaktadır (Kışoğlu, 2009). Bu tanımlardan farklı olarak Altun (2005) okuryazarlık, toplumdaki bilgi, beceri ve sosyal kuralları anlama, yorumlama ve paylaşma aracıdır. Günümüzde okuryazarlık, yazı sembolleri ile gerçekleştirilen bir eylem olmanın çok ötesinde, pek çok zihinsel beceriyi, dili kullanarak gerçekleştirilen iletişim becerilerini ve tutumlarını ifade eden bir eğitim terimidir (Aşıcı, 2009). Okuryazarlık, bireyin çevresine uyum sağlaması, karşılaştı̆̆ sorunları çözmesi, doğru karar vermesi için gerekli bilgilere ulaşması ve bu bilgileri doğru biçimde kullanmak amacıyla teknolojiyi ve bilgiye ulaşma araçlarını kullanmasıdır (Nergis, 2011).

Sanat okuryazarlığ 1 ise sanat eğitimi alan bireylerin sanata ilişkin kavramları bilmeyi sanatsal bilgi ve uygulamaları günlük hayatına aktarabilmesidir. Kuşkusuz okuryazarlık kavramları içerisinde sanat okuryazarlığı sanat eğitimi alan bireyler için ayrı bir öneme sahiptir.

Yücetoker (2014) sanat okuryazarlığını küreselleşen dünyada, doğrudan parçası olunan yerel sanat algısıyla dolaylı olarak erişilebilen evrensel sanatlar arasında birleştirici bir ilişki kurabilmeyi, sanatı meslek edinmiş bireylerin yaşamlarında ihtiyaç duyabilecekleri bilgiye erişebilmeyi ve bu bilgileri uygulamaya aktarabilmeyi sağlayan bir okuryazarlık türü olarak tanımlamıştır. Yücetoker'e göre sanat okuryazarlı̆ğına sahip bir birey sanat hakkındaki eksik kalan bilgileri nerede ve nasıl bulabileceğini bilen, araştırması gereken bilgilere hangi kaynaktan ve nereden ulaşabileceğini kavramış ulaştığı bilgileri kavramsal bir çerçevede değerlendirebilen bu bilgileri çalışmasında doğru şekilde kullanabilen ve yapacağı uygulamaları edindiği bilgilerle birleștirebilendir.

Bu doğrultuda sanat okuryazarlığının sanat eğitimi alan öğrencilere kazandırılması ve geliştirilmesi gereken bir beceri olduğu söylenebilir. $\mathrm{Bu}$ nedenle sanat eğitimi alan öğrencilerin sanat okuryazarlığı durumlarının incelenmesi ve geliştirilmesine yönelik çalışmaların yapılması sanat eğitiminin günümüzün ihtiyaç ve beklentilerine cevap vermesi açısından alana katkı sağlayacağı düşünülmektedir.

\section{Amaç}

$\mathrm{Bu}$ çalışmanın amacı Güzel sanatlar fakülteleri müzik bölümlerinde öğrenim gören bireylerin sanat okuryazarlık durumlarını çeşitli değişkenlere göre anlamlı farklılık gösterip göstermediğini incelemektir. Bu amaçla aşağıdaki sorulara cevap aranmıştır.

\section{Alt Amaçlar}

Üniversite öğrencilerinin sanat okuryazarlık durumları;

1. Cinsiyete

2. Sinifa 
3. Öğrenim gördükleri üniversiteye

4. Sanat kitapları okumaktan hoşlanma durumuna göre

5. Kütüphanede araştırma yapmayı sevme durumuna göre anlamlı bir farklılık göstermekte midir?

\section{Önem}

Günümüzde giderek önem kazanan okuryazarlık kavramlarından biri olan sanat okuryazarlığı sanat eğitimi alan bireylerde bulunması gereken özelliklerden biridir. Sanat eğitimi alan bireylerin sanat okuryazarlığı durumlarının incelenmesi bu anlamda önemlidir. Müzik eğitimi alan bireylerin teknik bilgi ve donanıma sahip olmalarının yanında sanat okuryazarlığg yüksek bireyler olması bu anlamda beklenen bir durumdur. Mesleki müzik eğitimi alan bireylerin sanat okuryazarlığı durumlarının incelendiği bu çalışmanın sanat eğitimi alan bireylerin daha nitelikli yetişmelerinde alana katkıda bulunacağı düşünülmektedir.

\section{Yöntem}

\section{Araştırma Modeli}

Çalışmada nicel araştırma yöntemlerinden tarama modeli kullanılmıştır. Genel tarama modelleri, çok sayıda elemandan oluşan bir evrende, genel bir yargıda bulunmak için, evrenin tümü ya da ondan alınacak bir grup ya da örneklem üzerinde yapılan taramadır (Karasar, 2005, s.79). Tarama modelleri, bir grubun özelliklerinin belirlenmesi için yapılan çalışmalardır (Büyüköztürk, Kılıç Çakmak, Akgün, Karadeniz ve Demirel, 2009, s.16).

\section{Araştırma Grubu}

2018-2019 eğitim öğretim yılında Kırşehir Ahi Evran Üniversitesi Neşet Ertaş Güzel Sanatlar Fakültesi müzik bölümünde öğrenim gören 1. Sınıf 17, 2. Sınıf 28 öğrenci ile Nevşehir Hacı Bektaş Veli Üniversitesi Güzel Sanatlar Fakültesi müzik bölümünde öğrenim gören 1.sınıf 31, 2.sınıf 26 olmak üzere toplam 102 öğrenci oluşturmaktadır.

\section{Veri Toplam Aracı}

Çalışmada Yücetoker (2014) tarafından geliştirilen "Sanat Okuryazarlığı Ölçeği” kullanılmıştır. Toplam 26 maddeden oluşan ölçekteki seçenekler; "Hiç Zorlanmıyorum” için 5, "Zorlanmıyorum” için 4, "Kararsızım” için 3, "Zorlanıyorum” için 2 ve "Çok Zorlanıyorum” için 1 şeklinde puanlanmıştır.

\section{Sanat Okuryazarlık Ölçeği}

Sanat Okuryazarlığg Bilgilerini Kullanmaya Yönelik Sorular

Sanat Okuryazarlığı Bilgi İhtiyacını Tanımlamaya Yönelik Sorular

Sanat Okuryazarlığı Bilgilerini Performansa Aktarmaya Yönelik Sorular

Sanat Okuryazarlığı Bilgilerine Ulaşmaya Yönelik Sorular olmak üzere 4 faktörden oluşmaktadır.

Güvenirlik hesaplamalarında, ölçeğin bütün olarak güvenirlik katsayısı .912 olarak belirlenmiştir. Araştırmacılar tarafından yapılan güvenirlik analizi sonucunda cronbach alpha değeri .903 bulunmuştur.

\section{Verilerin Toplanması}

Araştırmacılar tarafından hazırlanan "Kişisel Bilgi Formu” ve Yücetoker (2014) tarafından geliştirilen "Sanat Okuryazarlık Ölçeği” ile veriler toplanmıştır.

\section{Verilerin Analizi}

Verilerin analizinde SPSS istatistik paket programı kullanılmıştır. Verilerin normal dağılım gösterip göstermediğini tespit etmek için Kolmogrov-Simirnov testi yapılmıştır. Ayrıca betimsel analiz yapılmıştır.

Tablo 1

“Sanat Okuryazarlı̆̆ı Ölçeği” Ortalama Puanlarının Kolmogrov-Simirnov Test Sonuçları

\begin{tabular}{llllll}
\hline Ortalama Puan & $\mathbf{N}$ & $\overline{\mathbf{X}}$ & $\mathbf{S}$ & Kolmogrow-Simirnov & $\mathbf{p}$ \\
\hline & 102 & 3,55 &, 630 &, 567 &, 200 \\
\hline
\end{tabular}


Kolmogrov-Simirnov testi sonuçlarına göre veriler normal dağılım göstermektedir $(Z=.567, p>.05)$. Bu sebeple veriler analiz edilirken parametrik testler kullanılmıştır.

\section{Bulgular ve Yorumlar}

Araştırma grubunda yer alan öğrencilere, "Sanat okuryazarlı̆̆ Ölçeği” uygulanmış ve ölçekten elde edilen veriler, "betimsel istatistik" ile yorumlanmıştır. Her sanat okuryazarlık maddesinin yüzde dağılımlarına, ortalamalarına ve frekanslarına bakılmışıı (Tablo 3).

Tablonun yorumlanması için;

Ölçeğin aralık genişliği a = dizi genişliği / yapılacak grup sayısı, formülü ile hesaplanıp buna göre oluşturulan ölçekte; seçenekler ve sınırlar aşağıda verilmiştir.

Tablo 2

Ölçeğin Ăğrlık, Seçenek ve Sinır Değerleri

\begin{tabular}{ccc}
\hline Ă̆ırlık & Seçenekler & Sinır \\
\hline 5 & Hiç zorlanmiyorum & $4.21-5.00$ \\
4 & Zorlanmıyorum & $3.41-4.20$ \\
3 & Kararsızım & $2.61-3.40$ \\
2 & Zorlanıyorum & $1.81-2.60$ \\
1 & Çok zorlaniyorum & $1.00-1.80$ \\
\hline
\end{tabular}

Tablo 3

Sanat Okuryazarlığı Ölçeği ve Alt Faktörlerinin Betimsel Analizi

\begin{tabular}{lcccccc}
\hline & $\mathbf{N}$ & Minimum & Maximum & $\overline{\mathbf{X}}$ & $\mathbf{S}$ & Maddeler \\
\hline Faktör 1 & 102 & 1,50 & 4,90 & 3,3510 &, 71487 & $2,5,6,10,11,15,18,22$, \\
& & & & & & 25,26 \\
Faktör 2 & 102 & 1,40 & 5,00 & 3,4412 &, 78719 & $1,4,12,13,24$ \\
Faktör 3 & 102 & 1,83 & 5,00 & 3,7320 &, 70209 & $14,16,17,19,20,21$ \\
Faktör 4 & 102 & 2,00 & 5,00 & 3,8706 &, 74443 & $3,7,8,9,23$ \\
Ölçeğin Geneli & 102 & 1,65 & 4,85 & 3,5562 &, 63052 & \\
\hline
\end{tabular}

Güzel sanatlar fakültesi öğrencilerinin sanat okuryazarlığı ölçeğinden aldıkları puanların ortalamalarına bakıldığında 1. Faktör olan "sanat okuryazarlık bilgilerini kullanma" faktöründe yer alan maddelerde kararsız oldukları $(\overline{\mathrm{X}}=3,35), 2$. Faktör olan "sanat okuryazarlık bilgi ihtiyacını tanımlama" faktöründe yer alan maddelerde zorlanmadıklarını $(\overline{\mathrm{X}}=3,44)$, 3. Faktör olan "sanat okuryazarlık bilgilerini performansa aktarma" faktöründe yer alan maddelerde zorlanmadıklarını $(\overline{\mathrm{X}}=3,73)$, 4. Faktör olan "sanat okuryazarlık bilgilerine ulaşma" faktöründe yer alan maddelerde yine zorlanmadıklarını $(\overline{\mathrm{X}}=3,87)$ belirtmişlerdir. Ölçeğin genel olarak ortalaması incelendiğinde 3,55 ortalamayla sanat okuryazarlık durumlarına zorlanmadıkları yönünde karar vermişlerdir.

2. Üniversite öğrencilerinin sanat okuryazarlık durumlarının cinsiyet değişkenine göre bir farklılık olup olmadığı ölçeği oluşturan alt faktörlerden alınan ortalama puanlar dikkate alınarak ilişkisiz ölçümler için t-testi sonuçları Tablo 4'te verilmiştir. 
Tablo 4

Üniversite Öğrencilerinin Sanat Okuryazarlık Durumlarının Cinsiyet Değişkenine Göre t-Testi Sonuçları

\begin{tabular}{|c|c|c|c|c|c|c|c|}
\hline Ölçek/Alt Faktörler & Cinsiyet & $\mathbf{N}$ & $\overline{\mathbf{X}}$ & $\mathbf{S}$ & Sd & $\mathbf{t}$ & $\mathbf{p}$ \\
\hline \multirow[t]{2}{*}{ Bilgilerini Kullanma } & $\mathrm{K} 1 \mathrm{z}$ & 49 & 3,24 & ,69 & \multirow[t]{2}{*}{100} & \multirow[t]{2}{*}{1,506} & \multirow[t]{2}{*}{,135 } \\
\hline & Erkek & 53 & 3,45 &, 72 & & & \\
\hline \multirow{2}{*}{$\begin{array}{l}\text { Bilgi İhtiyacını } \\
\text { Tanımlama }\end{array}$} & $\mathrm{K}_{1 \mathrm{z}}$ & 49 & 3,35 & ,66 & \multirow[t]{2}{*}{100} & \multirow[t]{2}{*}{1,113} & \multirow[t]{2}{*}{,268 } \\
\hline & Erkek & 53 & 3,52 &, 88 & & & \\
\hline \multirow{2}{*}{$\begin{array}{l}\text { Bilgilerini Performansa } \\
\text { Aktarma }\end{array}$} & $\mathrm{K}_{1 \mathrm{z}}$ & 49 & 3,68 & ,72 & \multirow[t]{2}{*}{100} & \multirow[t]{2}{*}{,667 } & \multirow[t]{2}{*}{, 506} \\
\hline & Erkek & 53 & 3,77 & ,68 & & & \\
\hline \multirow[t]{2}{*}{ Bilgilerine Ulaşma } & $\mathrm{K} 1 \mathrm{z}$ & 49 & 3,69 &, 72 & \multirow[t]{2}{*}{100} & \multirow[t]{2}{*}{2,299} & \multirow[t]{2}{*}{,024 } \\
\hline & Erkek & 53 & 4,03 &, 73 & & & \\
\hline \multirow{2}{*}{$\begin{array}{l}\text { Sanat Okuryazarlığı } \\
\text { Ölçeği }\end{array}$} & $\mathrm{K}_{1 \mathrm{z}}$ & 49 & 3,45 &, 59 & \multirow[t]{2}{*}{100} & \multirow[t]{2}{*}{1,615} & \multirow[t]{2}{*}{, 109} \\
\hline & Erkek & 53 & 3,65 & ,65 & & & \\
\hline
\end{tabular}

Tablo 4'e göre güzel sanatlar fakültesi öğrencilerinin sanat okuryazarlık ölçeği ortalama puanları ölçeğin "sanat okuryazarlığı bilgilerine ulaşma" faktöründe cinsiyet değişkenine göre anlamlı farklılık göstermektedir $(\mathrm{t}=2,299$; $\mathrm{p}<.05)$. Bu anlamlı farklılık erkek öğrencilerin lehinedir $(\overline{\mathrm{X}}=4,03)$.

3. Üniversite öğrencilerinin sanat okuryazarlık durumlarının sınıf değişkenine göre anlamlı bir farklılık gösterip göstermediğini saptamak için ölçeğin tamamı ve ölçeği oluşturan alt faktörlerden alınan ortalama puanlar ile ilişkisiz ölçümler için t-testi yapılmıştır. Sonuçlar Tablo 5'te verilmiştir.

Tablo 5

Üniversite Öğrencilerinin Sanat Okuryazarlık Durumlarının Sınıf Değişkenine Göre t-Testi Sonuçları

\begin{tabular}{|c|c|c|c|c|c|c|c|}
\hline $\begin{array}{l}\text { Ölçek/Alt } \\
\text { Faktörler } \\
\end{array}$ & Sinıf & $\mathbf{N}$ & $\overline{\mathbf{X}}$ & $\mathbf{S}$ & Sd & $\mathbf{t}$ & $\mathbf{p}$ \\
\hline \multirow{2}{*}{$\begin{array}{l}\text { Bilgilerini } \\
\text { Kullanma }\end{array}$} & 1 & 37 & 3,38 &, 60 & \multirow[t]{2}{*}{100} & \multirow[t]{2}{*}{,406 } & \multirow[t]{2}{*}{,686 } \\
\hline & 2 & 65 & 3,32 &, 77 & & & \\
\hline \multirow{2}{*}{$\begin{array}{l}\text { Bilgi İhtiyacını } \\
\text { Tanımlama }\end{array}$} & 1 & 37 & 3,49 & ,65 & \multirow[t]{2}{*}{100} & \multirow[t]{2}{*}{,489 } & \multirow[t]{2}{*}{,626 } \\
\hline & 2 & 65 & 3,41 &, 85 & & & \\
\hline \multirow{2}{*}{$\begin{array}{l}\text { Bilgilerini } \\
\text { Performansa } \\
\text { Aktarma }\end{array}$} & 1 & 37 & 3,71 & 63 & \multirow[t]{2}{*}{100} & \multirow[t]{2}{*}{, 171} & \multirow[t]{2}{*}{,865 } \\
\hline & 2 & 65 & 3,74 &, 74 & & & \\
\hline \multirow[t]{2}{*}{ Bilgilerine Ulaşma } & 1 & 37 & 3,95 &, 80 & \multirow[t]{2}{*}{100} & \multirow[t]{2}{*}{,881 } & \multirow[t]{2}{*}{,380 } \\
\hline & 2 & 65 & 3,82 &, 70 & & & \\
\hline \multirow{2}{*}{$\begin{array}{l}\text { Sanat } \\
\text { Okuryazarlığı } \\
\text { Ölçeği }\end{array}$} & 1 & 37 & 3,59 &, 55 & \multirow[t]{2}{*}{100} & \multirow[t]{2}{*}{,450 } & \multirow[t]{2}{*}{,654 } \\
\hline & 2 & 65 & 3,53 &, 67 & & & \\
\hline
\end{tabular}


Tablo 5'e göre üniversite öğrencilerinin sanat okuryazarlık durumlarının sınıf değişkenine göre ölçeğin tamamı ve alt faktörleri arasında anlamlı bir farklılık göstermemektedir ( $\mathrm{p}>.05)$.

4. Üniversite öğrencilerinin sanat okuryazarlık durumlarının üniversite değişkenine göre anlamlı bir farklılık gösterip göstermediğini saptamak için ölçeğin tamamı ve ölçeği oluşturan alt faktörlerden alınan ortalama puanlar ile ilişkisiz ölçümler için t-testi yapılmıştır. Sonuçlar Tablo 6’da verilmiştir.

Tablo 6

Üniversite Öğrencilerinin Sanat Okuryazarlık Durumlarının Üniversite Değişkenine Göre t-Testi Sonuçları

\begin{tabular}{|c|c|c|c|c|c|c|c|}
\hline $\begin{array}{l}\text { Ölçek/Alt } \\
\text { Faktörler }\end{array}$ & Üniversite & $\mathbf{N}$ & $\overline{\mathbf{X}}$ & $\mathbf{S}$ & Sd & $\mathbf{t}$ & $\mathbf{p}$ \\
\hline \multirow{2}{*}{$\begin{array}{l}\text { Bilgilerini } \\
\text { Kullanma }\end{array}$} & Kırşehir Ahi Evran & 45 & 3,48 &, 64 & \multirow[t]{2}{*}{100} & \multirow[t]{2}{*}{1,691} & \multirow[t]{2}{*}{,094 } \\
\hline & Nevşehir Hacı Bektaş & 57 & 3,24 &, 75 & & & \\
\hline \multirow{2}{*}{$\begin{array}{l}\text { Bilgi } \\
\text { İhtiyacını } \\
\text { Tanımlama }\end{array}$} & Kırşehir Ahi Evran & 45 & 3,52 &, 70 & \multirow[t]{2}{*}{100} & \multirow[t]{2}{*}{,898 } & \multirow[t]{2}{*}{,372 } \\
\hline & Nevşehir Hacı Bektaş & 57 & 3,37 &, 84 & & & \\
\hline \multirow{2}{*}{$\begin{array}{l}\text { Bilgilerini } \\
\text { Performansa } \\
\text { Aktarma }\end{array}$} & Kırşehir Ahi Evran & 45 & 3,94 &, 62 & \multirow[t]{2}{*}{100} & \multirow[t]{2}{*}{2,806} & \multirow[t]{2}{*}{, $006 *$} \\
\hline & Nevşehir Hacı Bektaş & 57 & 3,56 &, 71 & & & \\
\hline \multirow{2}{*}{$\begin{array}{l}\text { Bilgilerine } \\
\text { Ulaşma }\end{array}$} & Kırşehir Ahi Evran & 45 & 3,95 &, 72 & \multirow[t]{2}{*}{100} & \multirow[t]{2}{*}{1,024} & \multirow[t]{2}{*}{,308 } \\
\hline & Nevşehir Hacı Bektaş & 57 & 3,80 & ,76 & & & \\
\hline \multirow{2}{*}{$\begin{array}{l}\text { Sanat } \\
\text { Okuryazarlığg } \\
\text { Ölçeği }\end{array}$} & Kırşehir Ahi Evran & 45 & 3,68 &, 55 & \multirow[t]{2}{*}{100} & \multirow[t]{2}{*}{1,901} & \multirow[t]{2}{*}{,060 } \\
\hline & Nevşehir Hacı Bektaş & 57 & 3,45 & 66 & & & \\
\hline
\end{tabular}

Tablo 6'ya göre güzel sanatlar fakültesi öğrencilerinin sanat okuryazarlık ölçeği ortalama puanları, ölçeğin "sanat okuryazarlığı bilgilerini performansa aktarma" faktöründe üniversite değişkenine göre anlamlı farklılık göstermektedir $(\mathrm{t}=2,806 ; \mathrm{p}<.05)$. Bu anlamlı farklılık Kırşehir Ahi Evran Üniversitesi öğrencilerinin lehinedir $(\overline{\mathrm{X}}=3,94)$.

6. Üniversite öğrencilerinin sanat okuryazarlıklarının sanat kitapları okumaktan hoşlanma durumuna göre anlamlı bir farklılık gösterip göstermediğini saptamak için ölçeğin tamamı ve ölçeği oluşturan alt faktörlerden alınan ortalama puanlar ile ilişkisiz ölçümler için t-testi yapılmıştır. Sonuçlar Tablo 7'de verilmiştir. 
Tablo 7

Üniversite Öğrencilerinin Sanat Okuryazarlık Durumlarının Sanat Kitapları Okumaktan Hoşlanma Durumuna Göre t-Testi Sonuçları

\begin{tabular}{|c|c|c|c|c|c|c|c|}
\hline $\begin{array}{l}\text { Ölçek/Alt } \\
\text { Faktörler }\end{array}$ & $\begin{array}{c}\text { Hoşlanma } \\
\text { durumu }\end{array}$ & $\mathbf{N}$ & $\overline{\mathbf{X}}$ & $\mathbf{S}$ & Sd & $\mathbf{t}$ & $\mathbf{p}$ \\
\hline \multirow{2}{*}{$\begin{array}{l}\text { Bilgilerini } \\
\text { Kullanma }\end{array}$} & Evet & 61 & 3,51 &, 72 & \multirow[t]{2}{*}{100} & \multirow[t]{2}{*}{2,990} & \multirow[t]{2}{*}{, $004^{*}$} \\
\hline & Hayır & 41 & 3,10 &, 62 & & & \\
\hline \multirow{2}{*}{$\begin{array}{l}\text { Bilgi İhtiyacını } \\
\text { Tanımlama }\end{array}$} & Evet & 61 & 3,65 &, 74 & \multirow[t]{2}{*}{100} & \multirow[t]{2}{*}{3,545} & \multirow[t]{2}{*}{, $001^{*}$} \\
\hline & Hayır & 41 & 3,12 &, 75 & & & \\
\hline \multirow{2}{*}{$\begin{array}{l}\text { Bilgilerini } \\
\text { Performansa } \\
\text { Aktarma }\end{array}$} & Evet & 61 & 3,84 & 67 & \multirow[t]{2}{*}{100} & \multirow[t]{2}{*}{2,049} & \multirow[t]{2}{*}{, $\mathbf{0 4 3}^{*}$} \\
\hline & Hayır & 41 & 3,56 & ,71 & & & \\
\hline \multirow{2}{*}{$\begin{array}{l}\text { Bilgilerine } \\
\text { Ulaşma }\end{array}$} & Evet & 61 & 3,90 &, 73 & \multirow[t]{2}{*}{100} & \multirow[t]{2}{*}{,620 } & \multirow[t]{2}{*}{, 536} \\
\hline & Hayır & 41 & 3,81 & ,76 & & & \\
\hline \multirow{2}{*}{$\begin{array}{l}\text { Sanat } \\
\text { Okuryazarlığg } \\
\text { Ölçeği }\end{array}$} & Evet & 61 & 3,69 & ,62 & \multirow[t]{2}{*}{100} & \multirow[t]{2}{*}{2,813} & \multirow[t]{2}{*}{, $006 *$} \\
\hline & Hayır & 41 & 3,34 &, 59 & & & \\
\hline
\end{tabular}

Tablo 7' ye göre güzel sanatlar fakültesi öğrencilerinin sanat okuryazarlık ölçeği ortalama puanları, ölçeğin "sanat okuryazarlığı bilgilerini kullanma", "sanat okuryazarlığı bilgi ihtiyacını tanımlama", "sanat okuryazarlığ1 bilgilerini performansa aktarma" alt faktörleri ve sanat okuryazarlığı ölçeğin tamamına ait ortalama puanları sanat kitapları okumaktan hoşlanma durumuna göre anlamlı farklılık göstermektedir $(\mathrm{p}<.05)$. Bu anlamlı farklılık sanat kitaplarını okumaktan hoşlanan öğrenciler lehinedir.

6.Üniversite öğrencilerinin sanat okuryazarlık durumlarının kütüphanede araştırma yapmayı sevme durumuna göre bir farklılık olup olmadığına yönelik ölçeğin tamamı ve alt faktörlerinden alınan ortalama puanlara yönelik ilişkisiz ölçümler için t-testi sonuçları Tablo 8'de verilmiştir.

Tablo 8

Üniversite Öğrencilerinin Sanat Okuryazarlık Durumlarının Kütüphanede Araştırma Yapmayı Sevme Durumuna Göre t-Testi Sonuçları

\begin{tabular}{|c|c|c|c|c|c|c|c|}
\hline $\begin{array}{l}\text { Ölçek/Alt } \\
\text { Faktörler }\end{array}$ & $\begin{array}{l}\text { Kütüphanede } \\
\text { araştırma } \\
\text { yapmayı sevme } \\
\text { durumu }\end{array}$ & $\mathbf{N}$ & $\overline{\mathbf{X}}$ & $\mathbf{S}$ & Sd & $\mathbf{t}$ & $\mathbf{p}$ \\
\hline \multirow{2}{*}{$\begin{array}{l}\text { Bilgilerini } \\
\text { Kullanma }\end{array}$} & Evet & 42 & 3,55 &, 77 & \multirow[t]{2}{*}{100} & \multirow[t]{2}{*}{2,408} & \multirow[t]{2}{*}{, 018} \\
\hline & Hayır & 60 & 3,21 &, 63 & & & \\
\hline \multirow{2}{*}{$\begin{array}{l}\text { Bilgi } \\
\text { İhtiyacını } \\
\text { Tanımlama }\end{array}$} & Evet & 42 & 3,57 &, 90 & \multirow[t]{2}{*}{100} & \multirow[t]{2}{*}{1,405} & \multirow[t]{2}{*}{,163 } \\
\hline & Hayır & 60 & 3,35 & ,68 & & & \\
\hline \multirow{2}{*}{$\begin{array}{l}\text { Bilgilerini } \\
\text { Performansa } \\
\text { Aktarma }\end{array}$} & Evet & 42 & 3,82 &, 79 & \multirow[t]{2}{*}{100} & \multirow[t]{2}{*}{1,077} & \multirow[t]{2}{*}{, 284} \\
\hline & Hayır & 60 & 3,66 & ,62 & & & \\
\hline \multirow{3}{*}{$\begin{array}{l}\text { Bilgilerine } \\
\text { Ulaşma }\end{array}$} & Evet & 42 & 4,03 &, 79 & \multirow[t]{2}{*}{100} & \multirow[t]{2}{*}{1,870} & \multirow[t]{2}{*}{,064 } \\
\hline & Hayır & 60 & 3,75 & ,69 & & & \\
\hline & Evet & 42 & 3,70 &, 71 & 100 & 2,093 & ,039* \\
\hline
\end{tabular}




\begin{tabular}{|c|c|c|c|c|}
\hline $\begin{array}{l}\text { Sanat } \\
\text { Okuryazarlığı } \\
\text { Ölçeği }\end{array}$ & Hayır & 60 & 3,44 &, 54 \\
\hline
\end{tabular}

Tablo 8'e göre güzel sanatlar fakültesi öğrencilerinin ölçeğin "sanat okuryazarlığı bilgilerini kullanma" alt faktörü ve sanat okuryazarlığı ölçeğin tamamına ait ortalama puanları kütüphanede araştırma yapmayı sevme durumuna göre anlamlı farklılık göstermektedir $(\mathrm{p}<.05)$. Bu anlamlı farklılık kütüphanede araştırma yapmayı seven öğrenciler lehinedir.

\section{Sonuç ve Tartışma}

Güzel Sanatlar fakülteleri öğrencilerinin sanat okuryazarlığı ölçeğinin genel ortalaması dikkate alındığında ölçekte yer alan maddelere "zorlanmadıkları" şeklinde cevap vermişlerdir. Çalışma sonucunda araştırma grubunda yer alan öğrenciler arasında erkek öğrencilerin sanat okuryazarlığının kız öğrencilere göre daha yüksek olduğu belirlenmiştir. Benzer şekilde Kurtaslan Yıldırım (2017) Güzel sanatlar lisesi öğrencilerinin sanat okuryazarlık düzeylerini çeşitli değişkenler açısından incelediği çalışmasında cinsiyete göre sanat okuryazarlığı ölçeğinin alt boyutlarından bilgileri kullanma, Bilgi ihtiyacını tanımlama ve Bilgilerini performansa aktarma boyutlarında erkek öğrenciler lehine anlamlı bir farklılık tespit etmiştir.

Yapılan çalışmanın sonucundan farklı olarak Okan Akın ve Yücetoker (2016) resim iş eğitimi öğrencilerinin sanat okuryazarlığı düzeylerini belirlemek amacıyla yaptıkları çalışmalarında cinsiyet değişkenine göre eşit düzeyde olduklarını, Mentiş Köksoy (2018a) ise sanat okuryazarlık düzeylerinin cinsiyet göre anlamlı farklılık göstermediğini belirtmiştir. Mentiş Köksoy (2018b) eğitim fakültesi öğrencilerinin sanat okuryazarlık düzeylerini incelediği çalışmasında cinsiyet değişkenine göre anlamlı farklılık göstermediğini belirlemiştir.

Çalışmanın bir diğer sonucunda öğrencilerin sanat okuryazarlık durumları sınıf düzeyine göre ölçeğin tamamı ve alt faktörleri arasında anlamlı bir farklılık göstermemektedir. Mentiş Köksoy (2018a) çalışmasında sınıf düzeyi ile sanat okuryazarlığı arasında anlamlı bir farklılık olmadığını belirlemiştir. Mentiş Köksoy (2018b) yaptığı diğer bir çalışmasında da eğitim fakültesi öğrencilerinin sanat okur yazarlık düzeyleri sınıf değişkenine göre anlamlı bir farklılık göstermemektedir. Kurtaslan Yıldırım (2017) çalışmasında sınıf düzeyine göre anlamlı bir farklılık bulmamıştır. Bu sonuçlar yapılan çalışmayı desteklemektedir. Diğer taraftan Okan Akın ve Yücetoker (2016) sınıf düzeyine göre sanat okuryazarlık düzeyi arasında pozitif bir ilişki olduğunu, Özer (2018) güzel sanatlar fakültesi müzik, resim ve seramik bölümü ögrrencilerinin sanat okuryazarlığı düzeylerini belirlemek amacıyla yaptığ çalışma sonucunda sınıf düzeyinin yükselmesinin sanat okuryazarlığ 1 düzeyini artırdığını, Yücetoker (2015) güzel sanatlar eğitimi müzik ve resim bölümü öğrencilerinin sanat okuryazarlığını incelediği çalışmasında sınıf düzeyinin yükselmesi sanat okuryazarlığı düzeyini de yükselttiği sonucuna varmıştır.

Çalışmanın bir diğer sonucunda sanat okuryazarlık ölçeği ortalama puanları, ölçeğin "sanat okuryazarlığı bilgilerini performansa aktarma" faktöründe üniversite değişkenine göre anlamlı farklılık göstermektedir. Bu anlamlı farklılık Kırşehir Ahi Evran Üniversitesi öğrencilerinin lehinedir.

Çalışmanın bir başka sonucunda Sanat okuryazarlığı bilgilerini kullanma”, "sanat okuryazarlığı bilgi ihtiyacını tanımlama", "sanat okuryazarlığı bilgilerini performansa aktarma" alt faktörleri ve sanat okuryazarlığı ölçeğin tamamına ait ortalama puanları sanat kitapları okumaktan hoşlanma durumuna göre anlamlı farklılık göstermektedir. Mentiş Köksoy (2018a) Öğrencilerinin sanat okuryazarlık durumlarının sanat kitapları okumaktan hoşlanma durumuna göre ölçeğin bilgilerini kullanma, bilgi ihtiyacını tanımlama, bilgilerini performansa aktarma alt boyutlarında anlamlı farklılık tespit etmiştir. Bu farklılık sanat kitapları okumaktan hoşlanan öğrenciler lehinedir. Bilgilere ulaşma alt boyutunda anlamlı bir farklılık yoktur. Mentiş Köksoy (2018b) eğitim fakültesi öğrencilerinin sanat okuryazarlık durumlarının sanat kitapları okuyan öğrenciler lehine daha yüksek olduğunu belirlemiştir. Özer (2018) sanat kitapları okumaktan hoşlanan öğrencilerin sanat okuryazarlık düzeyinin hoşlanmayan öğrencilere göre yüksek olduğunu, Okan Akın ve Yücetoker (2016) sanat kitapları okumaktan hoşlanan öğrencilerin sanat okuryazarlık düzeylerinin hoşlanmayan öğrencilerden yüksek olduğunu belirlemişlerdir. Benzer şekilde Yücetoker (2015) çalışmasında sanat kitapları okumaktan hoşlanan öğrencilerin sanat okuryazarlık düzeylerinin hoşlanmayan öğrencilere göre daha yüksek olduğunu belirlemiştir. Belirtilen çalışmaların bulguları yapılan çalışmayı destekler niteliktedir.

Çalışmada elde edilen son bulguya göre Ölçeğin "sanat okuryazarlığı bilgilerini kullanma" alt faktörü ve sanat okuryazarlığı ölçeğin tamamına ait ortalama puanları kütüphanede araştırma yapmayı sevme durumuna göre anlamlı farklılık göstermektedir. Okan Akın ve Yücetoker (2016) kütüphane araştırması yapmaktan hoşlanan öğrencilerin hoşlanmayanlara göre sanat okuryazarlık düzeyinin daha yüksek olduğunu, benzer şekilde Özer (2018) kütüphane araştırması yapmaktan hoşlanan öğrencilerin araştırma yapmaktan hoşlanmayan öğrencilere 
göre sanat okuryazarlık düzeyleri yüksektir. Mentiş Köksoy (2018a) sanat okuryazarlığı düzeyinin kütüphanede araştırma yapmayı seven öğrenciler lehine anlamlı farklılık gösterdiğini tespit etmiştir.

\section{Öneriler}

1. Sanat eğitimi veren kurumlarda sanat okuryazarlığı kazandırmaya yönelik seminer, sempozyum ve benzeri çalışmalar yapılabilir. Öğrencilerin sanatsal araştırmalara ve etkinliklere aktif katılımları sağlanarak eleştirel ve yaratıcı becerileri geliştirilebilir.

2. Sanat okuryazarlığı durumunu araştıran geniş perspektifli çalışmalar yapılarak sanat eğitimi alan bireylerin sanat alanı farklılıklarının sanat okuryazarlığına etkisi incelenebilir. Elde edilen sonuçlar nitel çalışmalarla daha derinlemesine araştırılabilir. Bu sayede sanat eğitimi alan bireylerin sanat okuryazarlıklarını geliştirmeye yönelik somut adımlar atılabilir.

\section{Kaynakça}

Afacan, Ş. ve Şentürk, N. (2016). Okul öncesi ve sınıf eğitimi anabilim dallarına yönelik müzik okuryazarlığı Ölçeğinin Geliştirilmesi. International Journal of Eurasia Social Sciences, 7(25), 228-247.

Altun, A. (2005). Gelişen teknolojiler ve yeni okuryazarlıklar. Ankara: Anı Yayınları

Aslan, L. ve Deniz, J. (2011). İlköğretim mezunu öğrencilerin müzik okuryazarlık düzeyleri. Marmara Üniversitesi Atatürk Ĕ̆itim Fakültesi Ĕ̆itim Bilimleri Dergisi, 43, 25-34.

Aşıcı, M. (2009). Kişisel ve sosyal bir değer olarak okuryazarlık. Değerler Eğitimi Dergisi, 7(17), 9-26.

Aydın, F. ve Silik, Y. (2018). Teknoloji okuryazarlığı tarihsel bir betimleme. Ihlara Ĕ̆gitim Araştırmaları Dergisi (IHEAD), 3(2), 107-126.

Büyüköztürk, Ş., Çakmak, E. K., Akgün, Ö. E., Karadeniz, Ş. ve Demirel, F. (2009). Bilimsel araştırma yöntemleri (3. Baskl). Ankara: Pegem Akademi.

Çakmak, E.E. (2019). Öğretmenlerin medya okuryazarlık düzeylerinin incelenmesi. Sınırsız Eğitim ve Araştırma Dergisi, 4(3), 300-316.

Karasar, N. (2005). Bilimsel araştırma yöntemi: Kavramlar, ilkeler ve teknikler (15. Baskı). Ankara: Nobel Yayıncılık.

Kaya, M. ve Bacanak, A. (2013). Fen ve teknoloji öğretmen adaylarının düşünceleri: Fen okuryazarı birey yetiştirmede öğretmenin yeri. Dicle Üniversitesi Ziya Gökalp Ĕ̆itim Fakültesi Dergisi, 21, 209-228.

Keefe, E. B., ve Copeland, S. R. (2011). What is Literacy? The power of a definition. Research \& Practice for Persons with Severe Disabilities, 36(3-4), 92-99. https://doi.org/10.2511/027494811800824507

Kışoğlu, M. (2009). Öğrenci merkezli öğretimin öğretmen adaylarının çevre okuryazarlı̆̆ı düzeyine etkisinin araştırılması. Yayımlanmamış doktora tezi, Atatürk Üniversitesi, Erzurum.

Kolburan, Geçer, A. ve Dağ, F. (2010). Üniversite öğrencilerinin bilgisayar okur-yazarlık düzeylerinin belirlenmesi Kocaeli Üniversitesi Örneği. Yüzüncü Yıl Üniversitesi Ĕgitim Fakültesi Dergisi, 7(1), 20-44.

Kurtaslan Yıldırım, H. (2017). Evaluation of art literacy levels of students who study in fine arts high school in terms of variables. Ekev Akademi Dergisi, Y11 21, Say1 70, 39-56.

Mentiş, Köksoy, A. (2018a). Investigation of art literacy levels of fine arts education students. Educational Research and Reviews, 13(8), 319-327. https://doi.org/10.5897/ERR2018.3517

Mentiş, Köksoy, A. (2018b). Examination of Art literacy levels of students studying in the education faculties. Journal of Education and Training Studies, 6(5), 101-110. https://doi.org/10.11114/jets.v6i5.3168

Nergis, A. (2011). Okuryazarlık kültürü ve değişen okuryazarlık türleri. International Online Journal of Educational Sciences, 3(3), 1133-1154.

Okan Akın, N. ve Yücetoker, İ. (2016). Sanat okur-yazarlığı ölçeğinin resim-iş eğitimi anabilim dalında uygulanması. VIII. Uluslararası Eğitim Araştırmaları Kongresi, 5-6 Mayıs, Çanakkale Onsekiz Mart Üniversitesi, Çanakkale.

Örs, E. ve Baş, B. (2018). İkinci sınıf öğrencilerinin görsel okuryazarlığı üzerine bir araştırma. Ana Dili Eğgitim Dergisi, 6(1), 95-113. 
Özer, B. (2018). Güzel sanatlar fakültelerindeki öğrencilerin sanat okuryazarlık düzeyleri üzerine bir araştırma Ekev Akademi Dergisi, 73, 441-450.

San, İ. (1982). Sanat eğitimi. Ankara Üniversitesi Eğitim Bilimleri Fakültesi Dergisi, 15(1), 215-226.

Uçan, A. (1996). İnsan ve müzik insan ve sanat eğitimi (2. Basım). Ankara: Müzik Ansiklopedisi Yayınları.

Uyar, A. ve Temiz, A. (2019). Sınıf Öğretmenlerinin çevre okuryazarlık düzeylerinin belirlenmesi ve bazı değiş̧kenler açısından incelenmesi. Uluslararası Sosyal Araştırmalar Dergisi, 112(66), 954-961.

Yenice, N., Yavaşoğlu, N., Alpak Tunç, G. ve Candarlı Arıkoz, F. (2019). Öğretmen adaylarının bilgi okuryazarlık düzeyleri ile bilimsel araştırmaya yönelik tutumlarının incelenmesi. Buca Eğitim Fakültesi Dergisi, 47, 7795.

Yücetoker, İ. (2014). Sanat okuryazarlı̆̆ı ölçeğinin hazırlanması ve geliştirilmesi. Sanat Eğitimi Dergisi, 2(1), 112-126.

Yücetoker,İ. (2015). Güzel sanatlar eğitimi öğrencilerinin sanat okuryazarlı̆̆ı düzeylerinin değerlendirilmesi. Ekev Akademi Dergisi, 62, 669-676.

\section{Extended Abstract}

\section{Introduction}

Art is a phenomenon that takes place in every period of human life. In a simple expression, art is a unique aesthetic whole, which is combined with emotions, thoughts and impressions, certain situation phenomena and events, with a specific purpose and method according to a certain understanding of beauty (Uçan, 1996). Children and young people who are educated and educated by experiencing multi-dimensional and multidimensional phenomena will develop a tolerant and tolerant personality who can interpret and comprehend the events and phenomena, are open to innovations, all kinds of contemporary developments, are prone to understand new developments in science, technology and social change processes. It is certain (San, 1982). Music education, which is one of the most important dimensions of art education, necessitates to have an artistic point of view, to reach artistic knowledge, to think multi-dimensional by analyzing and synthesizing besides providing technical knowledge and skills specific to the field. As can be seen from these statements, many literacy concepts specific to many fields have emerged. These include music literacy, media literacy, computer literacy, technology literacy, science literacy. On the other hand, art literacy is the ability of individuals who are educated in art to transfer their knowledge of art to daily life. Undoubtedly, within the concepts of literacy, art literacy has a special importance for individuals who receive art education. Within the scope of the study which examined the art literacy status of the students who took vocational music education, the answers to these questions were sought. Art literacy status of the students in the research group;

1. Gender

2. Class

3. To the university where they study

4. Depending on the liking of reading art books

5. Does the library show a significant difference according to the liking of doing research?

\section{Research Model}

In the study, screening model which is one of the quantitative research methods was used. General screening models, in a universe consisting of a large number of elements, to make a general judgment, the whole universe or a group or sample to be taken from the screening is done (Karasar, 2005, p.79).

\section{Research Group}

In the 2018-2019 academic year, the research group was first grade 17 2nd grade 28 students studying in the music department of Neşet Ertaş Fine Arts Faculty of Kırşehir Ahi Evran University and 28th grade students in the Nevşehir Hacı Bektaş Veli University Faculty of Fine Arts. There are 102 students in total.

\section{Data collection tool}

Art literacy scale, which consists of 26 items, was developed by Yücetoker (2014). 


\section{Data Analysis}

SPSS statistical package program was used for data analysis. Kolmogrov-Simirnov test was used to determine whether the data showed normal distribution. In addition, descriptive analysis was performed. According to Kolmogrov-Simirnov test results, the data shows normal distribution. For this reason, parametric tests were used to analyze the data.

\section{Results And Comments}

1. When the general average of the scale was examined by the students of the faculty of fine arts from the art literacy scale, they decided that their art literacy status was not forced with 3.55 average.

2. The mean scores of art literacy scale of the faculty of fine arts students showed significant difference in the ulaşma access to art literacy information" factor according to gender variable $(t=2,299 ; \mathrm{p}<.05)$. This significant difference is in favor of male students.

3. Art literacy status of university students does not show a significant difference between the whole scale and sub-factors according to the class variable.

4. The average scores of art literacy scale of the students of the Faculty of Fine Arts, kullanma using the art literacy knowledge", tanımlama defining the need for art literacy knowledge", aktarma transferring the art literacy knowledge to performance ve and the average scores belonging to the whole art scale were meaningful according to the status of reading art books. differed $(\mathrm{p}<.05)$. This significant difference is in favor of students who like to read art books.

5. The sub-factor of kullanma using art literacy knowledge ve and the mean scores of the whole art scale of the faculty of fine arts students differed significantly according to the liking of doing research in the library $(\mathrm{p}<.05)$. This significant difference is in favor of students who like to do research in the library.

\section{Suggestions}

Seminars, symposiums and similar activities can be conducted in institutions providing art education to provide art literacy. Students' active participation in artistic research and activities can be ensured by developing critical and creative skills. The effects of differences in the art field of the individuals who receive art education on art literacy can be examined by conducting studies with a wide perspective on the state of art literacy. The results obtained can be investigated in more depth with qualitative studies. In this way, concrete steps can be taken to improve the art literacy of individuals receiving art education. 